\title{
Incorporating Indigenous Students’ Cultural Knowledge More Productively in Mathematics and Science Classrooms: One Focus for Pre-Service Teacher Education Research and Practice
}

\section{Philemon Chigeza}

\author{
Hilary Whitehouse
}

School of Education, James Cook University, Cairns

\begin{abstract}
There is widespread agreement that Indigenous students' cultural knowledge is desirably incorporated into curriculum and pedagogical practice. Classroom research shows Aboriginal and Torres Strait Islander learners can use the cognitive tools of their cultural community to engage with school science. We looked towards our own practice as teacher educators to investigate the question: how can pre-service teachers explore how Indigenous cultural knowledge can be used more productively in mathematics and science classrooms? Teachers across Australia are now regulated by the National Professional Standards for Teachers (NPST). Teacher education is now regulated by the National Graduate Teacher Standards (AITSL 2011). Standard 1.4 requires that graduating teachers are able to "demonstrate broad knowledge and understanding of the impact of culture, cultural identity and linguistic background on the education of students from Aboriginal and Torres Strait Islander backgrounds". Standard 2.4 requires that graduating teachers "demonstrate broad knowledge and understanding of and respect for Aboriginal and Torres Strait Islander histories, cultures and languages". In this paper we present an account of our present understanding of capacity building practises, which are those pedagogies that draw on Indigenous students' cultural resources: cultural disposition, community knowledge and cultural capital. A key purpose of the presentation is to emphasise the socially negotiated, cultural and embedded nature of meaning-making in science education and how this can be made more apparent given the current focus on implementing the National Professional Standards for Teachers and the new Australian Curriculum.
\end{abstract}

\section{Introduction}

$\mathrm{T}$ eachers across Australia are now to be regulated by the National Professional Standards for Teachers (NPST). Teacher education, the area in which we work as academics, is now regulated by the National Graduate Teacher Standards (AITSL 2011). Standard 1.4 requires that graduating teachers are able to "demonstrate broad knowledge and understanding of the impact of culture, cultural identity and linguistic background on the 
education of students from Aboriginal and Torres Strait Islander backgrounds”. Standard 2.4 requires that graduating teachers "demonstrate broad knowledge and understanding of and respect for Aboriginal and Torres Strait Islander histories, cultures and languages”. While established teachers tend to have "fear, resistance and concern about these particular focus areas" (Ma Rhea, Anderson and Atkinson 2012, p. 51), work can be done in pre-service education to normalise the practice of teaching for Aboriginal and Torres Strait Islander learning in the classroom.

This is important, especially given that all students at school in Australia (and by inference their teachers) are subject to extensive performance measures. One of the unfortunate outcomes of standardized measures is that groups of people who perform below a decided benchmark can be judged as 'deficit' in terms of educational achievement. According to the 2012 NAPLAN data, the academic performance of Aboriginal and Torres Strait Islander students in some schools in regional and remote areas is amongst the lowest nationally. When the results are explained through a deficit model then students and their families are blamed for having poor educational motivation, low interest and low ability levels (Sara, 2007) and this blame game is conducted without reference to properly examining student experiences of formal learning environment or instructional practices.

The content and processes of formal school curriculum have always been indicative of knowledge / power relations in society. Under the new National Professional Standards Standards 1.4 and 2.4, teachers and pre-service teachers are asked to deal with knowledge that was previously not privileged within standardised curriculum (Ma Rhea et al. 2012). And engage with the national Australian Curriculum (version 5.1) F-10 cross curriculum priority: Aboriginal and Torres Strait Islander histories and culture (ACARA 2013). This is a partial step in the move towards full recognition and reconciliation of different Australian knowledge and positionality of knowledge. We say a 'partial step' because Lowe and Yunkaporta's (2013, p. 5) detailed analysis of the Aboriginal and Torres Strait Islander content currently in the Australian Curriculum concluded, "public education is still a long way from engaging with Aboriginal and Torres Strait Islander epistemologies”. And while teachers are asked to engage with Indigenous content, it can be seen as "weak ... tokenistic and overwhelmingly unresponsive to historical and contemporary realities" (p. 12). The Australian Curriculum does not fully "provide students with an informed understanding of the effects of colonisation, or the similarities between the colonial power's justification for annexation, loss of sovereignty, and the forced removal of Indigenous peoples from their Country” (p.11).

Nonetheless, teachers and pre-service teachers are being asked to work in epistemological spaces that remain contested and politicised. TheEAustralian Curriculum is far from being a perfect document, but it does tend offer greater certainty within the long established discipline of science where we have found Aboriginal and Torres Strait Islander adolescents are highly capable learners who bring a rich array of cultural resources to the classroom (Chigeza and Whitehouse 2010).

\section{The Need for Culturally Enabling Modes of Practice}

Aboriginal and Torres Strait Islander students are capable learners of the western disciplines (see Warren and Miller 2013). Therefore deficit models of student capability and achievement tend to be more expressions of the ways in which power relations have been historically constituted. We know deficit models do not serve the social goal of improving 
educational attainment. Nor do they raise performance scores for historically marginalised groups of students. As teacher educators, we are highly critical of science education practices that persistently reproduce deficit models of any student achievement (or attainment). Pedagogies that lead to deficit models and student 'blame' actually fail to acknowledge or legitimise or build upon the cultural resources students bring to the classroom (Chigeza 2011).

We used an action research cycle (Kemmis and McTaggart 2000) to investigate a pedagogical approach to science and mathematics education that focused on capacity building. Our original study was with two Year 9 classes of Torres Strait Islander students $(n=44)$ and inquired into the cultural knowledge students drew on for developing their understandings; the pedagogical strategies that enabled students to learn, know and (re)produce knowledge; and how the structure of the state mandated science curriculum enhanced or limited their agency. We formed a view that a capacity building pedagogy draws specifically on students' cultural resources: their cultural dispositions, community knowledge and cultural capital. Drawing on cultural resources in classroom practice strongly affects student agency to positively develop their scientific learning dispositions. This type of capacity building pedagogy recognises the socially negotiated and embedded nature of meaning making in science education.

The most interesting feature of learning science concepts was linguistic in dimension. Students ranged for being highly able to learn the concepts of energy and force as taught in English within conventional classroom practice; to a large group partially able to engage with science learning in English but who also was abandoned English in favour of Torres Strait Creole to explain their scientific understandings to one another; to a group of students who could not use English at all with facility. This last group students did, however, show evidence of knowing how to apply the concepts using direct actions and 'dramatisations' when speaking in Creole, even if they could not reproduce their science understandings in English at the standard expected in Year 9. Such students are at risk of not being able to participate adequately in formal science curriculum. Yet they can learn science when their cultural resources - everyday (home) languages, experiences and knowledge systems - are thoughtfully incorporated into formal school science teaching and learning.

Current curriculum does not cater for students with limited facility in English who are required to negotiate from their vernacular languages and ways of knowing into the language and knowledge of formal science. A science curriculum that accommodates the multiple language dimensions and ways of knowing of old and emerging Indigenous cultures is much more likely to enable students to develop their capacity successfully. But as Ma Rhea et al. (2012) point out the development of "reliable" knowledge base and skills set for teachers to equitably enable student learning still needs far more systemic support and concentrated effort across Australia.

\section{From Everyday Ways of Knowing to Formal Mathematics and Science Knowing}

Aboriginal and Torres Strait Islander students must negotiate their traditional knowledge systems, a number of home languages, school science taught in Standard English, and their own emerging youth cultures and dialects. Home language and Creole thinking students learning a disciplined science curriculum in Standard Australian English need to be outstanding field negotiators in order to be positioned as successful learners within formal education systems. A staged model to conceptualise our thinking and understanding on how 
students might accommodate and negotiate these differentiated knowledge systems is presented below, though in reality it's not as staged and is much more fluid than the model. As Nakata (2002) says, the cultural interface has many woven, competing and conflicting facets.

Negotiation at the interface for Indigenous students learning school mathematics and science (first published in Chigeza, 2008)

\begin{tabular}{|l|l|l|}
\hline $\begin{array}{l}\text { An Indigenous student’s everyday ways of } \\
\text { talking and knowing }\end{array}$ & $\begin{array}{l}\text { Mathematics and Science ways } \\
\text { of talking and knowing }\end{array}$ \\
\hline $\begin{array}{l}\text { An Indigenous } \\
\text { student with limited } \\
\text { facility in Standard } \\
\text { Australian English } \\
\text { student with facility } \\
\text { in Standard } \\
\text { Australian English }\end{array}$ & $\begin{array}{l}\text { An Indigenous student becoming } \\
\text { competent in school } \\
\text { mathematics and science ways } \\
\text { of talking, thinking and doing }\end{array}$ \\
\hline & & \\
\hline Legend & & \\
\hline
\end{tabular}

Science curriculum and pedagogy that fails to affirm students' cultural knowledge disables students. As science educators, we need to address this deficit model or token approach by developing pedagogies that affirm these students' lived languages, experiences and knowledge in their learning.

\section{Cultural Resources Are Brought to the Classroom}

Bourdieu (1996) argues habitus and cultural capital inform agency, which is the idea that an individual is equipped with the ability to understand and control their own actions, regardless of the circumstances of their lives. Habitus refers to a set of dispositions, or patterns of thought, behaviour, and taste created and formulated as a result of internalization of culture. Culture is an individual's habit of mind; the development of a whole society; or the whole way of life of a group of people (Rojek, 2007). Cultural capital therefore is a set of culturally authorised attributes, skills and awards an individual acquires and includes forms of knowledge (including scientific knowledge) and forms of language. Yosso (2005) conceptualised cultural capital for Indigenous groups of people as community cultural wealth - this includes the aspirational, navigational, social, linguistic, familial and resistant capital nurtured within communities.

In our research we reconciled Bourdieu's and Yosso's notions of capital as ‘cultural resources' which, as cultural disposition, community knowledge and cultural capital, when brought to the classroom, influences the agency of a student. Rogoff (2003) writes that human development occurs on at least three levels: personal, interpersonal and cultural/institutional, and that these three levels are inherently interwoven in all human activities. In science classrooms, teachers work at all three levels simultaneously. Sewell 
(1992), in analysing the relationship between resources, agency and power, suggested that learners are agentic when they transpose resources learned in one context to another. Cultural resources brought to the classroom can be leveraged into meaningful science learning. All this 'works' because, as Jenkins (2002) points out, cultural sociology views agency and structure as dialectical - structure influences human action, and humans are capable of changing the social structures they inhabit.

Enabling classroom are those where Aboriginal and Torres Strait Islander students' cultural resources are valued, recognized and legitimized (Ma Rhea et al. 2012). Classroom contexts where students' cultural resources are marginalized, ignored or forbidden (as was the case until recently) are strongly disabling. Any deficit model of Aboriginal and Torres Strait Islander learners is challenged when pedagogies are deployed that explicitly value the cultural resources students bring with them to the classroom. This is recognised by the National Professional Standards for Teachers in the Focus Areas 1.4 and 2.4. Though the standards many not go far enough (e.g. Lowe and Yunkaporta 2013), the standards give teachers something to work with in that they do draw explicit educational attention to the social and cultural realities of classrooms in tropical Australia.

\section{Why a Capacity Building Approach Can Work}

Bang et al. (2012) wrote it well when they said: "Our classroom research has focused on designs for science learning based in an expansive view of human meaning-making as fundamentally heterogeneous and multi-voiced, both within and between socially and historically constituted communities”. This too has been our project. For Sutherland (2003), capacity building in links science concept learning with the everyday lives of the students and their community, and also cues teachers to identify the congruencies and the sometimes (inevitable) incongruence between school and home. Eade (1997) argued that since students' experiences and knowledge play a central role in learning, marginalised students have the right and the capacity to challenge authority if learning environments are not enabling for them. In regional, rural and remote areas of Australia, intending teachers can expect to meet significant numbers of Aboriginal and Torres Strait Islander students in their classrooms, as well as students from around the Pacific. It is therefore incumbent on us as pre-service educators, that we draw pre-service teachers' attention to pedagogies that will encourage enabling classroom practice. After all, it is far more rewarding to work in classrooms where the learners are engaged and feel they are acknowledged and valued than to experience the opposite, especially in the high stakes discipline of science.

A capacity building pedagogy needs to satisfy two conditions. The first is that the elements composing a student's cultural resources (their cultural disposition, their community knowledge and their cultural capital, which includes home languages and Creoles) are explicitly acknowledged and seen to be valued. The second is that educators use this array of cultural resources to build a student's capacity to learn the formal disciplines (Chigeza, 2011). Cobern (1996) advised that Indigenous students may close their minds to explanations that completely reject their own cultural beliefs so it is much better pedagogy to effectively negotiate learning spaces between what can be quite different categories of knowledge for the same concepts. For example, traditional cooking practices can be used to teach energy concepts. And drawing on a home language, such as Torres Strait Islander Creole, and drawing on non-verbal communication skills (gestures and the like) in a Year 9 school science classroom is useful for negotiating then developing conceptual meaning in physical science. Using students' cultural resources helps students to be better disposed towards 
learning science. That is, to develop their scientific 'disposition' and become possessed of and positive about discipline knowledge.

\section{Pre-Service Education and Capacity Building Pedagogy}

The next stage in our considerations is to examine what we do as teacher educators. How can we use our research findings within our own practice? How can we reshape pre-service teacher knowledge and understanding of culture and how it works to enable or disable learning in diverse classrooms? Pre-service teachers are looking for meaningful careers as educators. The burning question is always, 'how do I survive and thrive in a classroom?'

In pre-service teacher education, the value of exploring the cultural dimensions of pedagogy is in learning how culture influences how an individual or a group make sense of a very fast changing world. As teacher educators we have to pay attention to Fischer's (2003, p. 23) comment that "life is outrunning the pedagogies in which we have been trained". We know that peoples of different cultures use different styles of communicating and of representing their knowledge and that culture strongly influences ways of talking, thinking and engaging with new science learning. The pre-service teacher facing a career in highly diverse classrooms can flourish when s/he possess a deeper knowledge about the interactions between knowing, learning and culture. To know that students' lived experiences are the foundations for their academic learning (Gee 2005) is powerful knowledge for a successful teaching career.

Teacher educators can do a number of things to better prepare future teachers for successful classroom careers working with Aboriginal and Torres Strait Islander students. We can explicitly teach how to recognise, investigate, draw on and draw out the cultural resources in classroom contexts. Pre-service teachers can learn strategies to make capacity building more apparent in their practice. As so many students from regional, rural and remote communities traverse intersecting knowledge and language systems on a daily basis, we can encourage pre-service teachers to think more extensively on how to engage Aboriginal and Torres Strait Islander cultural resources within science learning. We can point out that when it is difficult for all students to participate in class on an equal basis then any disenfranchised student can quickly become a resistant learner (Snively and Williams 2008). And resistant learners do not make for happy classroom experiences.

To change this is not only a matter of introducing Aboriginal and Torres Strait Islander knowledge into the science class. Change is also about enabling intending teachers to explicitly recognise the cultural resources students bring with them to the classroom, and to know how to find out about and access knowledge through the community knowledge keepers. Also, intending teachers have to have the confidence to say to their students, we will learn the powerful western ways of scientific knowing knowledge by drawing on the cultural resources you already possess. This includes having the confidence to engage with learning the disciplines through different languages and different modes of knowledge representation such as dance, drumming, yarning, storytelling, songs, rap; and teaching through well-liked activities such as community cooking and fishing as well as inviting members of the community into the science classroom. It also means, becoming familiar with local language(s).

According to Zevenbergen and colleagues (2008), students develop conceptual understanding when they are able to 'code switch' between their home language and instructional language 
representations. We found that even a limited knowledge of Torres Strait Creole on behalf of teachers worked for enhancing learning physical science concepts in our research school. Encouraging Year 9 students to talk about science in both Creole and English really did positively alter learning dispositions towards science. It is encouraging that at Yarrabah State School, near Cairns, Education Queensland has documented the use of Yarrie Lingo, the Creole language spoken in the community of Yarrabah (which has its origins in up to forty original Aboriginal and Torres Strait Islander languages) to assist non-Indigenous teaching staff and visitors engage with students and their parents across the curriculum. As McTaggart and Curro (2009) suggest, such types of language and cultural interchanges can resonate right across the formal curriculum in schools and across teacher education programs and can be considered highly enabling for concept learning.

\section{Conclusion}

We have argued that a specific and positive focus on capacity building practices within formal school education and within pre-service teacher education programs may significantly enhance the agency of the Aboriginal and Torres Strait Islander students to learn science. A capacity building approach shifts the perspective where the cultural knowledge, skills and abilities of students are recognised, acknowledged and drawn upon to teacher and learn scientific concepts. Teacher education is an important site for shifting old prejudices in science education and for making our way forward. When life outruns old pedagogies, new pedagogies must be found.

\section{Works Cited}

Aikenhead, G. S. (2006). Science education for everyday life: Evidence-based practice. New York, NY: Teachers College Press.

Bourdieu, P. (1986). The forms of capital. In J.G. Richardson (Ed.) Handbook of theory and research for the sociology of education. New York, NY: Greenwood Press.

Chigeza, P. (2011). Cultural resources of minority and marginalised students should be included in the school science curriculum. Cultural Studies of Science Education, Volume 6, Issue 2, Page 401- 412.

Chigeza, P., \& Whitehouse, H. (2010). Australian Torres Strait Islander students negotiate learning in Standard Australian English: A tentative case for also teaching and assessing in Creole: In D. Tippins, M. P. Mueller, M. van Eijck \& J. Adams (Eds), Cultural Studies and Environmentalism: The Confluence of EcoJustice, Place-based (Science) Education, and Indigenous Knowledge Systems. Netherlands: Springer.

Chigeza, P. (2008). Language negotiations Indigenous students navigate when learning science. Australian Journal of Indigenous Education, Vol 37, pp 91-97.

Cobern, W.W. (1996). Worldview theory and conceptual change in Science Education. Science Education, Vol 80, pp 579-610. 
Eade, D. (1997). Capacity building: An approach to people-centred development. Atlantic Highlands, NJ: Humanities Press International.

Fisher, M.M.J. (2003). Emergent forms of life and the anthropological voice. Chapel Hill, NC: Duke University Press.

Gee, J. P. (2005). An Introduction to Discourse Analysis: Theory and method, $2^{\text {nd }}$ Edition. New York, NY: Routledge.

Jenkins, R. (2002). Pierre Bourdieu: revised edition. New York, NY: Routledge.

Lowe, K. and T. Yunkaporta. 2013. The inclusion of Aboriginal and Torres Strait Islander content in the Australian National Curriculum: A cultural, cognitive and socio political evaluation. Curriculum Perspectives, 33, no. 1: 1 - 14.

Ma Rhea, Z., Anderson, P.J. and Atkinson, B. (2012). Final report: Improving teaching in Aboriginal and Torres Strait Islander education: National professional standards for teachers. Standard focus areas 1.4 and 2.4. Melbourne, VIC: Monash University. http://arrow.monash.edu.au/vital/access/manager/Repository/monash:11840

McTaggart, R., \& Curro, G. (2009). Book Language as a Foreign Language - ESL Strategies for Indigenous Learners. Report of research commissioned by the Queensland College of Teachers. Brisbane, QLD: Queensland College of Teachers.

Nakata, M. (2002). Indigenous knowledge and the cultural interface: Understanding issues at the intersection of knowledge and information systems. IFLA Journal, Vol 28. pp. 281-291.

Rogoff, B. (2003). The cultural nature of human development. New York, NY: Oxford University Press.

Rojek, C. (2007). Cultural Studies, Cambridge, UK: Polity Press.

Sara, C. (2007). Young, black and deadly: Strategies improving outcomes for Indigenous students. In M. Keeffe \& S. Carrington (Eds), Schools and diversity ( $2^{\text {nd }}$ ed) pp 74-89. Sydney, NSW : Pearson.

Sewell, W. H. J. (1992). A theory of structure: Duality, agency, and transformation. The American Journal of Sociology, Vol 98(1), pp. 1-29.

Snively, G. and Williams, L. (2005). The Aboriginal Knowledge and Science Education Research Project. In Roth, W-M. (ed.) Connections'05. Faculty of Education, University of Victoria, Canada. Online:

http://education2.uvic.ca/Research/conferences/connections2005/proceedings2005.pd f\#page $=241$

Snively, G. J., \& Williams, L. B. (2008). “Coming To Know”: Weaving Aboriginal and Western Science Knowledge, Language, and Literacy into Science Classroom. L1 Educational Studies in Language and Literature, Vol 8 (1), pp 109-133. 
Sutherland, D.L. (2003). The case for capacity building as a pedagogical goal in the science classroom. In D. L. Sutherland \& L. Sokal (Eds). Resiliency and capacity building in inner-city learning communities, Winnipeg, Manitoba, Canada: Portage \& Main Press.

Warren, E. and Miller, J. (2013). Young Australian Indigenous students’ effective engagement in mathematics: the role of language, patterns and structure. Mathematics Education Research Journal. Vol. 25(2), pp. 151- 171.

Yosso, T. J. (2005). Whose culture has capital? A critical race theory discussion of community cultural wealth. Race Ethnicity and Education, Vol 8, No. 1, pp 69 - 91.

Zevenbergen, R., Sullivan, P., Lerman, S., Boaler, J., Grootenboer, P., \& Niesche, R. (2008). Reforming pedagogy in remote Indigenous contexts. Curriculum Leadership, Vol 6, Issue 24. 